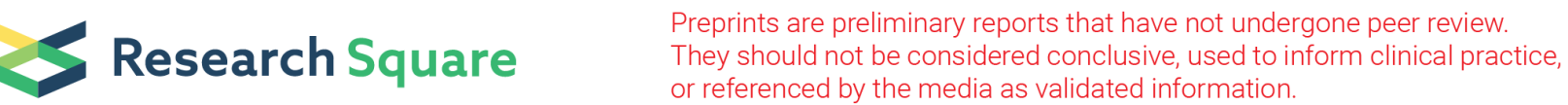

\section{Squamous cell carcinoma antigens (SCCAs) are sensitive biomarkers for atopic dermatitis in children and adolescents: a cross-sectional study}

\section{Junya Hirayama}

Mie University School of Medicine

Takao Fujisawa ( $\sim$ eosinophilosophy@gmail.com )

National Hospital Organization Mie National Hospital https://orcid.org/0000-0002-9196-9436

Mizuho Nagao

National Hospital Organization Mie National Hospital

Yu Kuwabara

National Hospital Organization Mie National Hospital

Keigo Kainuma

National Hospital Organization Mie National Hospital

Yoshinori Azuma

Sino-Test Corperation

Junya Ono

Sino-Test Corperation

Shoichiro Ohta

Saga University School of Medicine

Masahiro Hirayama

Mie University School of Medicine

Kenji Izuhara

Saga University School of Medicine

Research

Keywords: Atopic dermatitis, Biomarker, Squamous cell carcinoma antigens (SCCAs), Thymus and activation-regulated chemokine (TARC)

Posted Date: October 1st, 2020

DOI: https://doi.org/10.21203/rs.3.rs-83731/v1

License: (c) (1) This work is licensed under a Creative Commons Attribution 4.0 International License.

Read Full License 
Version of Record: A version of this preprint was published at Asia Pacific Allergy on January 1st, 2021. See the published version at https://doi.org/10.5415/apallergy.2021.11.e42. 


\section{Abstract}

Background We recently reported that squamous cell carcinoma antigen 2 (SCCA2) is a reliable biomarker for atopic dermatitis (AD) in children. To further clarify its utility, we investigated for possible effects of comorbid allergies and AD treatment on serum SCCA levels in children and adolescents.

Methods Volunteers aged less than 18 years were recruited through our website. Their allergic status was elucidated using the International Study of Asthma and Allergies in Childhood (ISAAC) questionnaire. We also recruited pediatric patients who needed to be hospitalized because of severe AD. The serum levels of SCCA1 and SCCA2 were measured by ELISAs. In the severe AD patients, the levels of thymus and activation-regulated chemokine (TARC), SCCA1 and SCCA2 were measured before and after hospitalization. The severity of AD was assessed using the severity scoring of atopic dermatitis (SCORAD) index.

Results A total of 576 participants (547 volunteers and 29 patients) were enrolled in the study. The levels of SCCA1 and SCCA2 were significantly higher in volunteers with mild AD and patients with severe AD than in healthy volunteers without allergic diseases. In contrast, the levels were not elevated in those who had mild bronchial asthma or mild allergic rhinitis without AD. TARC, SCCA1 and SCCA2 were decreased in patients with severe $A D$, reflecting clinical improvement in response to treatment. Linear regression analysis for predicting a decrease in the SCORAD index showed $R^{2}$ values of $0.16,0.38$ and 0.48 for TARC, SCCA1 and SCCA2, respectively..

Conclusions SCCAs, especially SCCA2, are sensitive biomarkers for detecting AD in children and adolescents, even in the mild stage, and for assessing the severity and response to treatment of severe AD.

\section{Background}

Atopic dermatitis (AD) is a chronic inflammatory skin disorder, and its increasing prevalence is a major public health concern. The goal of treatment of $A D$ is to control skin eruptions and bothersome symptoms, such as itching, so that patients can lead an uninterrupted social life with the best possible quality of life [1]. To achieve that goal, full control of skin inflammation is essential. However, accurate assessment of skin inflammation is sometimes difficult since a physician's visual examination may not always identify subclinical inflammation [2]. To date, many biomarkers for monitoring skin inflammation in $A D$ have been proposed [3]. However, there are few reliable biomarkers at present, and the American Academy of Dermatology even states that there are no specific biomarkers that can be recommended for diagnosis and/or assessment of disease severity [4].

Squamous cell carcinoma antigens (SCCAs) are serine proteinase inhibitors that belong to the serpin superfamily of proteins [5]. They are expressed in various epithelial tissues [6] and may be involved in epidermal barrier homeostasis $[7,8]$. They were originally purified from squamous cell carcinoma of the uterine cervix [9] and have been utilized as markers in various cancers [10-14]. Later, SCCA serum levels 
were found to be elevated in various inflammatory skin diseases, including AD [15-18]. Since SCCAs were found to be induced by Th2 cytokines, such as interleukin-4 (IL-4) and IL-13 [16], they may be potential biomarkers for $A D$ as downstream markers of Th2-type immune responses. Several studies suggested that measurement of SCCA1 and SCCA2 in the serum may be promising for evaluating/monitoring the clinical severity of $A D[16,19-23]$.

Recently, we and others in a multi-center study [23] reported the clinical utility of SCCA2 in a relatively large number of pediatric AD patients. However, the marker was not measured in patients with comorbid allergic diseases such as asthma and allergic rhinitis, which may confound interpretation of the data in $A D$ since most children with $A D$ have multiple allergic diseases. Here, we conducted a cross-sectional study to assess the utility of SCCA1 and SCCA2 in the pediatric population, focusing especially on comorbid allergies. We also assessed the relationship between their serum levels and the disease severity/treatment responses in patients with severe AD.

\section{Methods}

\section{Study participants and outcomes}

Volunteers aged less than 18 years were recruited through the Mie National Hospital website. Subjects were excluded from the study if they had a non-allergic chronic disease or an acute infectious disease. All volunteers completed the questionnaires of the International Study of Asthma and Allergies in Childhood (ISAAC) [24]. For this study, we used the validated Japanese version [25]. Based on the answers to the questions, the presence or absence of current (the most recent 12 months) symptoms of $A D$, bronchial asthma (BA) and allergic rhinitis (AR) was determined, and the volunteers were classified into the following 4 groups: healthy volunteers without $A D, B A$ or $A R$ (healthy group); those with $B A$ but not $A D$ (BA group); those with $A R$ but not $A D$ or $B A$ (AR group) and those with $A D$ (AD group 1). We also recruited patients who needed to be hospitalized because of severe AD (AD group 2). During hospitalization, patients were treated with emollients and topical corticosteroids according to clinical practice guidelines [1].

Blood samples were obtained from the study participants to measure the baseline serum levels of SCCA1 and SCCA2. Blood samples were obtained twice (i.e., at the beginning and end of hospitalization) from some patients with severe $A D$, and the serum levels of thymus and activation-regulated chemokine (TARC), as well as SCCA1 and SCCA2, were measured. TARC is a member of the Th2 type chemokine family and was reported to be a useful biomarker for AD [26-28]. The serum levels of TARC, SCCA1 and SCCA2 were measured using specific enzyme-linked immunosorbent assays (ELISAs) $[21,26]$. The disease severity in the patients with severe AD was also assessed at the beginning and end of hospitalization using the severity scoring of atopic dermatitis (SCORAD) index [29].

\section{Statistical analyses}


Baseline serum levels of SCCA1 and SCCA2 were summarized as the geometric mean and standard deviation (SD). The logarithmically transformed means were compared among the participant groups by analysis of variance. Tukey's multiple comparison test was used to assess all pairwise differences between the participant groups. For the severe AD patients, we calculated Spearman's correlation coefficients between the SCORAD index and the logarithmically transformed values of TARC, SCCA1 and SCCA2 levels, and between the decrease in the SCORAD index and the decrease in each of the logarithmically transformed biomarker levels. All data were analyzed using GraphPad Prism 8 (GraphPad Software, Inc.; CA, USA). All reported P values are two-sided.

\section{Results}

\section{Characteristics of subjects}

A total of 576 participants (547 volunteers and 29 severe AD patients) were enrolled in the study (Fig. 1). All participants were included in the analyses. Table 1 summarizes the demographics, gender, age and allergic comorbidities of the subjects. The patients were relatively younger than the volunteers, with mean (SD) ages of 4.0 (4.9) years in AD group 2, and ranging from 6.7 (2.1) to 9.3 (3.2) years in the other groups.

Table 1

Baseline characteristics of the study participants

\begin{tabular}{|c|c|c|c|c|c|}
\hline & \multicolumn{4}{|l|}{ Volunteers } & \multirow{2}{*}{$\begin{array}{l}\text { Patients } \\
\text { AD Group } 2 \\
(\mathrm{n}=29)\end{array}$} \\
\hline & $\begin{array}{l}\text { Healthy Group } \\
(\mathrm{n}=179)\end{array}$ & $\begin{array}{l}\text { BA Group } \\
(\mathrm{n}=58)\end{array}$ & $\begin{array}{l}\text { AR Group } \\
(\mathrm{n}=181)\end{array}$ & $\begin{array}{l}\text { AD Group } 1 \\
(n=129)\end{array}$ & \\
\hline Male (n, \%) & $86(48)$ & $35(60)$ & $97(54)$ & $63(49)$ & $15(52)$ \\
\hline Age (years, mean $\pm S D$ ) & $7.5 \pm 2.8$ & $6.7 \pm 2.1$ & $9.3 \pm 3.2$ & $8.0 \pm 3.5$ & $4.0 \pm 4.9$ \\
\hline \multicolumn{6}{|l|}{ Comorbidity } \\
\hline Atopic dermatitis (n, \%) & $0(0)$ & $0(0)$ & $0(0)$ & - & - \\
\hline Bronchial asthma (n, \%) & $0(0)$ & $58(100)$ & $0(0)$ & $6(5)$ & $2(7)$ \\
\hline Allergic rhinitis (n, \%) & $0(0)$ & $38(66)$ & $65(100)$ & $65(50)$ & $4(14)$ \\
\hline \multicolumn{6}{|c|}{$\begin{array}{l}\text { Abbreviations: } \mathrm{n}=\text { the number of participants; } \mathrm{SD}=\text { standard deviation; } \mathrm{AD}=\text { atopic dermatitis; } \mathrm{BA}= \\
\text { bronchial asthma; } \mathrm{AR}=\text { allergic rhinitis. }\end{array}$} \\
\hline \multicolumn{6}{|c|}{$\begin{array}{l}\text { Healthy group }=\text { healthy volunteers without allergic diseases; } B A \text { group }=\text { volunteers with } B A ; A R \text { group } \\
=\text { volunteers with } A R ; A D \text { group } 1=\text { volunteers with } A D ; A D \text { group } 2=\text { patients who needed to be } \\
\text { hospitalized because of severe } A D \text {. }\end{array}$} \\
\hline
\end{tabular}




\section{Serum levels of SCCA1 and SCCA2 in each allergic disease group}

Figure 2 and Table S1 show the serum levels of SCCA1 and SCCA2 in the 5 groups. Table S1 summarizes the pairwise comparisons between the groups. While the serum levels of SCCA1 and SCCA2 were similar among the healthy, BA and AR groups, they were significantly higher in AD groups 1 and 2 than in the healthy group $(p<0.0001)$. and also significantly higher $(p<0.0001)$ in $A D$ groups 1 and 2 than in the BA and AR groups. Finally, those serum levels were significantly higher in AD group 2 than in AD group 1 ( $p<$ 0.0001 ). The differences in their geometric means were $6.6 \mathrm{ng} / \mathrm{mL}$ for SCCA1 and $20.0 \mathrm{ng} / \mathrm{mL}$ for SCCA2.

\section{Reference and cut-off values for SCCA1 and SCCA2}

The healthy children were further divided into 3 age groups: $1-5,6-10$ and $11-17$ years old. Table S2 summarizes the descriptive statistics of SCCA1 and SCCA2 in those groups. Although SCCA1 and SCCA2 were slightly higher in the 2 younger groups, there were no significant differences among the groups. Next, we calculated the geometric mean and SD for all healthy volunteers. As a result, the reference values (geometric mean - 2SD to geometric mean + 2SD) of SCCA1 and SCCA2 were 0.45 to $1.91 \mathrm{ng} / \mathrm{mL}$ and 0.21 to $1.93 \mathrm{ng} / \mathrm{mL}$, respectively.

ROC analysis was performed to determine the diagnostic performance of the biomarkers in identifying $A D$ in the volunteer groups. The AUCs were 0.676 for SCCA1 and 0.715 for SCCA2. The cut-off levels based on the highest Youden index were 1.09 and $0.84 \mathrm{ng} / \mathrm{ml}$, respectively. The cut-off levels at $95 \%$ specificity were 1.65 and $1.5 \mathrm{ng} / \mathrm{ml}$, respectively (Table 2 ).

Table 2

Diagnostic performance of SCCA1 and SCCA2 for AD in the volunteer population

\begin{tabular}{|c|c|c|c|c|c|c|c|c|}
\hline & AUC & Cut-off & Sensi & ivity $(95 \% \mathrm{Cl})$ & Speci & city $(95 \% \mathrm{Cl})$ & $\mathrm{PPV}^{\dagger}$ & $\mathrm{NPV}^{\dagger}$ \\
\hline SCCA1 & 0.676 & 1.09 & 0.62 & $(0.53-0.70)$ & 0.68 & $(0.61-0.75)$ & 0.38 & 0.85 \\
\hline & $(0.613-0.738)$ & 1.65 & 0.26 & $(0.19-0.35)$ & 0.95 & $(0.91-0.98)$ & 0.62 & 0.81 \\
\hline SCCA2 & 0.715 & 0.84 & 0.61 & $(0.52-0.70)$ & 0.71 & $(0.64-0.77)$ & 0.39 & 0.86 \\
\hline & $(0.657-0.774)$ & 1.50 & 0.35 & $(0.27-0.44)$ & 0.95 & $(0.91-0.98)$ & 0.68 & 0.83 \\
\hline
\end{tabular}

\section{SCCA1 and SCCA2 in severe AD patients}

Blood samples were obtained at the beginning and end of hospitalization of 18 severe AD patients. During the treatment in the hospital, the serum levels of TARC, SCCA1 and SCCA2 decreased significantly in all patients (Figs. 3A, 3B and 3C, respectively) and correlated significantly with the SCORAD index 
(Figs. 3D, 3E, and 3F, respectively). Spearman's correlation coefficients were $0.6856,0.7513$ and 0.7885 , respectively. We also assessed the relationship between the decrease in the SCORAD index and the decreases in the serum levels of TARC, SCCA1 and SCCA2 (Figs. 3G, 3H and 3l, respectively). Among these biomarkers, a decrease in the SCCA2 level most strongly predicted improvement in the severity, i.e., a decrease in the SCORAD index, with $\mathrm{R}^{2}=0.476$.

\section{Discussion}

In this study, children and adolescents with AD showed significantly higher serum levels of SCCA1 and SCCA2 compared with healthy volunteers. The levels were not elevated in those with BA or AR without AD, indicating that SCCAs are specific markers for $A D$ in allergic children. Their levels were higher in $A D$ group 2 (patients with severe $A D$ ) than in $A D$ group 1 (volunteers with $A D$, presumably mild disease). We also found that the serum levels of SCCAs in AD group 2 correlated significantly with the SCORAD index, and decreases in their levels during treatment correlated well with decreases in the SCORAD index. The correlation indices were highest for SCCA2 compared with SCCA1 and TARC. These results indicate that SCCAs are reliable biomarkers for AD, and that the serum levels of SCCAs, especially SCCA2, predict the disease severity and treatment response.

TARC has been regarded as the most reliable biomarker of the severity of AD [3]. TARC is a ligand for CC chemokine receptor 4 , which is selectively expressed on Th2 type cells. It is produced by dendritic cells, endothelial cells and keratinocytes, and its overproduction leads to Th2 type cell accumulation at inflammation sites [30]. In contrast, SCCAs are induced by Th2 type cytokines such as IL-4 and IL-13 [16]. Therefore, SCCAs may reflect the "down-stream" of the immune response, which might lead to superiority of SCCAs in our study. The reason for the stronger correlation of the SCCA2 level with disease severity remains unclear. An earlier study showed that keratinocytes produced mainly SCCA2 upon stimulation with IL-4 or IL-13 [21]. This result may in part explain the superiority of SCCA2 over SCCA1 for disease activity.

In addition, serum TARC levels are high in children, especially infants [26]. Thus, it is necessary to have different reference and cut-off values for TARC in different age groups for clinical use. On the contrary, the serum levels of SCCAs in healthy children were similar among the different age groups in our study. Although the levels were slightly higher in the 2 younger groups, the differences were not statistically significant and were much smaller than those found for TARC [26]. In our previous report [23], we demonstrated the validity of a single cut-off at $1.6 \mathrm{ng} / \mathrm{ml}$ for SCCA2. We also determined the normal ranges and cut-off levels of SCCA1 and SCCA2, irrespective of age, which may be helpful in clinical application. Because different subject groups were recruited for determination of cut-off levels, i.e., only mild $A D$ in this study and more severe $A D$ in the previous study, the cut-off levels of SCCA2 were different. However, the cut-off level at $95 \%$ specificity was $1.5 \mathrm{ng} / \mathrm{ml}$ in this studyis close tothe $1.6 \mathrm{ng} / \mathrm{ml}$ in the previous study. 
An important finding in this study was that the serum levels of SCCAs correlated with the severity of AD. It is sometimes difficult to assess the severity and evaluate the outcome of a certain treatment because physicians' visual examinations are not always accurate [28]. Various instruments have been developed to measure the symptoms of $A D$, and several have been recommended as core outcome sets [31]. However, the main objective of the recommendation was to define the core outcome sets that should be used in clinical trials. These instruments are not suitable for use in daily clinical practice because their scoring systems are complex [32]. Accordingly, a simple and reliable biomarker for assessing disease severity would be a great breakthrough.

The serum levels of SCCAs were similar between healthy volunteers and those with BA or AR. In a study that included children with acute asthma, serum SCCA levels increased only in the acute phase of asthma exacerbation, while in the recovery phase they were similar to those in age-matched healthy children [33]. Another study found the SCCA levels to be elevated in BA patients compared with controls, but the difference was only $1 \mathrm{ng} / \mathrm{mL}$ [34]. Furthermore, serum SCCA levels in adult patients with AR caused by cedar pollen were similar to those in healthy adult volunteers, and the median level in patients with AR caused by Dermatophagoides farinaen was only $0.20 \mathrm{ng} / \mathrm{mL}$ higher than that in healthy volunteers [35]. Our present findings are consistent with those earlier results. However, serum levels of SCCAs were reported to be elevated in patients with psoriasis [17], so special attention needs to be paid to differential diagnosis of $A D$ from psoriasis.

This study has several limitations. First, we used the SCORAD index as a severity scale, but that is not considered to be a gold-standard severity scale [4]. Second, we did not assess the relationship between the disease severity and the serum levels of biomarkers in patients with mild or moderate AD. However, we previously reported the SCCA2 levels in that population of AD patients [23], and one of the purposes of this study was to clarify utility of SCCAs in AD children with comorbidities

In conclusion, the serum levels of SCCA1 and SCCA2 were elevated in children and adolescents with AD. In addition, the SCCA2 level correlated more strongly with the SCORAD index than the TARC or SCCA1 level. We think that SCCA2 has potential as a useful and reliable biomarker for assessing the severity of $A D$ in children and adolescents and their responses to treatment.

\section{Abbreviations}

AD: atopic dermatitis

AR: allergic rhinitis

BA: bronchial asthma

SCCA: squamous cell carcinoma antigen

SCORAD: severity scoring of atopic dermatitis 
TARC: thymus and activation-regulated chemokine

\section{Declarations}

\section{Ethics approval and consent to participate}

The study protocol was approved by the Ethics Committee of Mie National Hospital (Approval No: 24-1). All guardians of the participants provided written informed consent.

\section{Consent for publication}

All guardians of the participants provided written informed consent.

\section{Availability of data and materials}

The datasets used and/or analyzed during the current study are available from the corresponding author on reasonable request.

\section{Competing interests}

TF received lecture fees from Maruho Co., Ltd. and MSD Co., Ltd.. YA and JO are employees of Shino-Test Corporation. All other authors declare that they have no conflicts of interest.

\section{Funding}

This research was supported by a grant-in-aid from the Japan Agency for Medical Research and Development (AMED).

\section{Authors' contributions:}

Takao Fujisawa and Mizuho Nagao conceived the study. Junya Hirayama, Takao Fujisawa, Mizuho Nagao, Yu Kuwabara and Keigo Kainuma recruited the subjects and contributed to data collection. Yoshinori Azuma and Junya Ono conducted the assays. Junya Hirayama, Takao Fujisawa and Mizuho Nagao conducted the analyses of the data. Shoichiro Ohta and Kenji Izuhara contributed to interpretation of the data. Junya Hirayama and Takao Fujisawa wrote the manuscript. Masahiro Hirayama gave critical comments on the study design and manuscript. All the listed authors were involved in the review of the manuscript and approved the final content.

\section{Acknowledgments}

The authors would like to thank Ms. Sumiko Yoshikawa, Ms. Manami Negoro and Ms. Kyoko Nishinaka for their excellent technical assistance. Writing and editing assistance was provided by Kenichi Hayashi (Alamedic Co., Ltd.; Tokyo, Japan) under contract with the principal authors (JH, MN and TF). 


\section{References}

1. Katoh N, Ohya $Y$, Ikeda M, Ebihara T, Katayama I, Saeki H, et al. Clinical practice guidelines for the management of atopic dermatitis 2018. The Journal of dermatology. 2019;46(12):1053-101.

2. Tang TS, Bieber T, Williams HC. Are the concepts of induction of remission and treatment of subclinical inflammation in atopic dermatitis clinically useful? JAllergy Clinlmmunol. 2014;133(6):1615-25 e1.

3. Thijs J, Krastev T, Weidinger S, Buckens CF, de Bruin-Weller M, Bruijnzeel-Koomen C, et al. Biomarkers for atopic dermatitis: a systematic review and meta-analysis. Curr Opin Allergy Clin Immunol. 2015;15(5):453-60.

4. Eichenfield LF, Tom WL, Chamlin SL, Feldman SR, Hanifin JM, Simpson EL, et al. Guidelines of care for the management of atopic dermatitis: section 1. Diagnosis and assessment of atopic dermatitis. J Am Acad Dermatol. 2014;70(2):338-51.

5. Silverman GA, Bird PI, Carrell RW, Church FC, Coughlin PB, Gettins PG, et al. The serpins are an expanding superfamily of structurally similar but functionally diverse proteins. Evolution, mechanism of inhibition, novel functions, and a revised nomenclature. JBiolChem. 2001;276(36):33293-6.

6. Cataltepe S, Gornstein ER, Schick C, Kamachi Y, Chatson K, Fries J, et al. Co-expression of the squamous cell carcinoma antigens 1 and 2 in normal adult human tissues and squamous cell carcinomas. The journal of histochemistry and cytochemistry : official journal of the Histochemistry Society. 2000;48(1):113-22.

7. Sivaprasad U, Kinker KG, Ericksen MB, Lindsey M, Gibson AM, Bass SA, et al. SERPINB3/B4 contributes to early inflammation and barrier dysfunction in an experimental murine model of atopic dermatitis. J Invest Dermatol. 2015;135(1):160-9.

8. Sakata Y, Arima K, Takai T, Sakurai W, Masumoto K, Yuyama N, et al. The squamous cell carcinoma antigen 2 inhibits the cysteine proteinase activity of a major mite allergen, Der $\mathrm{p} 1$. JBiolChem. 2004;279(7):5081-7.

9. Kato $\mathrm{H}$, Torigoe T. Radioimmunoassay for tumor antigen of human cervical squamous cell carcinoma. Cancer. 1977;40(4):1621-8.

10. Shimura K, Mabuchi S, Yokoi T, Sasano T, Sawada K, Hamasaki T, et al. Utility of serum squamous cell carcinoma antigen levels at the time of recurrent cervical cancer diagnosis in determining the optimal treatment choice. J Gynecol Oncol. 2013;24(4):321-9.

11. Williams M, Swampillai A, Osborne M, Mawdsley S, Hughes R, Harrison M, et al. Squamous cell carcinoma antigen: a potentially useful prognostic marker in squamous cell carcinoma of the anal canal and margin. Cancer. 2013;119(13):2391-8.

12. Yin M, Hou Y, Zhang T, Cui C, Zhou X, Sun F, et al. Evaluation of chemotherapy response with serum squamous cell carcinoma antigen level in cervical cancer patients: a prospective cohort study. PLoS One. 2013;8(1):e54969. 
13. Chen IH, Liao CT, Wang HM, Huang JJ, Kang CJ, Huang SF. Using SCC antigen and CRP levels as prognostic biomarkers in recurrent oral cavity squamous cell carcinoma. PLoS One. 2014;9(7):e103265.

14. van Zijl F, Monserez DA, Korevaar TIM, Bugter O, Wieringa MH, Baatenburg de Jong RJ, et al. Postoperative value of serum squamous cell carcinoma antigen as a predictor of recurrence in sinonasal inverted papilloma. Clin Otolaryngol. 2017;42(3):528-35.

15. Campbell B, De'Ambrosis B. Squamous cell carcinoma antigen in patients with cutaneous disorders. J Am Acad Dermatol. 1990;22(4):639-42.

16. Mitsuishi K, Nakamura T, Sakata Y, Yuyama N, Arima K, Sugita Y, et al. The squamous cell carcinoma antigens as relevant biomarkers of atopic dermatitis. ClinExpAllergy. 2005;35(10):1327-33.

17. Watanabe Y, Yamaguchi Y, Komitsu N, Ohta S, Azuma Y, Izuhara K, et al. Elevation of serum squamous cell carcinoma antigen 2 in patients with psoriasis: associations with disease severity and response to the treatment. Br J Dermatol. 2016;174(6):1327-36.

18. Horiuchi Y, Tsukahara T, Otoyama K. Immunohistochemical study of elevated expression of squamous cell carcinoma (SCC)-related antigens in erythrodermic epidermis. The Journal of dermatology. 1994;21(2):67-72.

19. Kawashima H, Nishimata S, Kashiwagi Y, Numabe H, Sasamoto M, Iwatsubo H, et al. Squamous cell carcinoma-related antigen in children with atopic dermatitis. Pediatr Int. 2000;42(4):448-50.

20. Yamane Y, Moriyama K, Yasuda C, Miyata S, Aihara M, Ikezawa Z, et al. New horny layer marker proteins for evaluating skin condition in atopic dermatitis. Int Arch Allergy Immunol. 2009;150(1):89101.

21. Ohta S, Shibata R, Nakao Y, Azuma Y, Taniguchi K, Arima K, et al. The usefulness of combined measurements of squamous cell carcinoma antigens 1 and 2 in diagnosing atopic dermatitis. Annals of clinical biochemistry. 2012;49(Pt 3):277-84.

22. Okawa T, Yamaguchi Y, Kou K, Ono J, Azuma Y, Komitsu N, et al. Serum levels of squamous cell carcinoma antigens 1 and 2 reflect disease severity and clinical type of atopic dermatitis in adult patients. Allergol Int. 2018;67(1):124-30.

23. Nagao M, Inagaki S, Kawano T, Azuma Y, Nomura N, Noguchi Y, et al. SCCA2 is a reliable biomarker for evaluating pediatric atopic dermatitis. JAllergy ClinImmunol. 2018;141(5):1934-6 e11.

24. Asher MI, Keil U, Anderson HR, Beasley R, Crane J, Martinez F, et al. International Study of Asthma and Allergies in Childhood (ISAAC): rationale and methods. EurRespirJ. 1995;8(3):483-91.

25. Futamura M, Ohya $Y$, Akashi M, Adachi $Y$, Odajima $H$, Akiyama K, et al. Age-related prevalence of allergic diseases in Tokyo schoolchildren. Allergol Int. 2011;60(4):509-15.

26. Fujisawa T, Nagao M, Hiraguchi $Y$, Katsumata $H$, Nishimori H, Iguchi $K$, et al. Serum measurement of thymus and activation-regulated chemokine/CCL17 in children with atopic dermatitis: elevated normal levels in infancy and age-specific analysis in atopic dermatitis. Pediatr Allergy Immunol. 2009;20(7):633-41. 
27. Tamaki K, Kakinuma T, Saeki H, Horikawa T, Kataoka Y, Fujisawa T, et al. Serum levels of CCL17/TARC in various skin diseases. The Journal of dermatology. 2006;33(4):300-2.

28. Kataoka Y. Thymus and activation-regulated chemokine as a clinical biomarker in atopic dermatitis. The Journal of dermatology. 2014;41(3):221-9.

29. Severity scoring of atopic dermatitis: the SCORAD index. Consensus Report of the European Task Force on Atopic Dermatitis. Dermatology. 1993;186(1):23-31.

30. Saeki H, Tamaki K. Thymus and activation regulated chemokine (TARC)/CCL17 and skin diseases. J Dermatol Sci. 2006;43(2):75-84.

31. Gerbens LA, Prinsen CA, Chalmers JR, Drucker AM, von Kobyletzki LB, Limpens J, et al. Evaluation of the measurement properties of symptom measurement instruments for atopic eczema: a systematic review. Allergy. 2017;72(1):146-63.

32. de Bruin Weller MS, Knulst AC, Meijer Y, Bruijnzeel-Koomen CA, Pasmans SG. Evaluation of the child with atopic dermatitis. ClinExpAllergy. 2012;42(3):352-62.

33. Nishi N, Miyazaki M, Tsuji K, Hitomi T, Muro E, Zaitsu M, et al. Squamous cell carcinoma-related antigen in children with acute asthma. Ann Allergy Asthma Immunol. 2005;94(3):391-7.

34. Yuyama N, Davies DE, Akaiwa M, Matsui K, Hamasaki Y, Suminami Y, et al. Analysis of novel disease-related genes in bronchial asthma. Cytokine. 2002;19(6):287-96.

35. Suzuki K, Inokuchi A, Miyazaki J, Kuratomi Y, Izuhara K. Relationship between squamous cell carcinoma antigen and the clinical severity of allergic rhinitis caused by Dermatophagoides farinae and Japanese cedar pollen. Ann Otol Rhinol Laryngol. 2010;119(1):22-6.

\section{Figures}
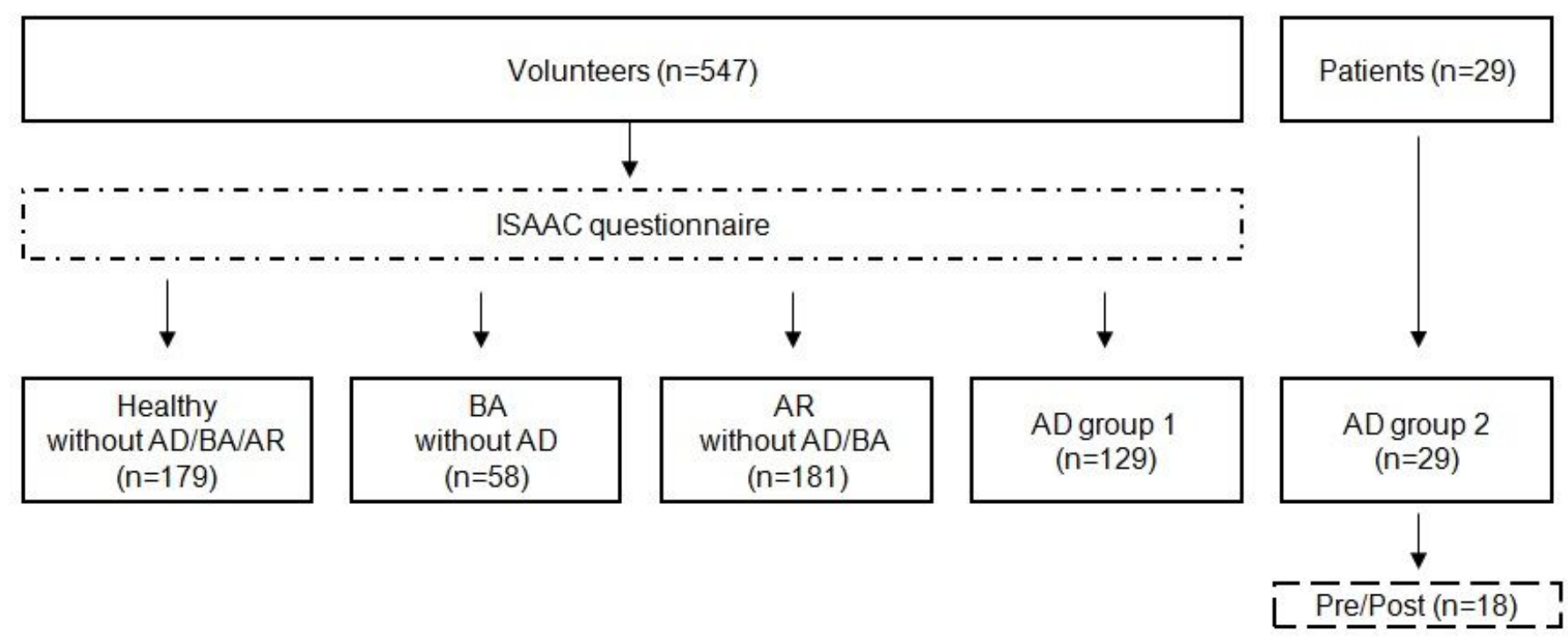
Figure 1

Subjects enrolled in the study
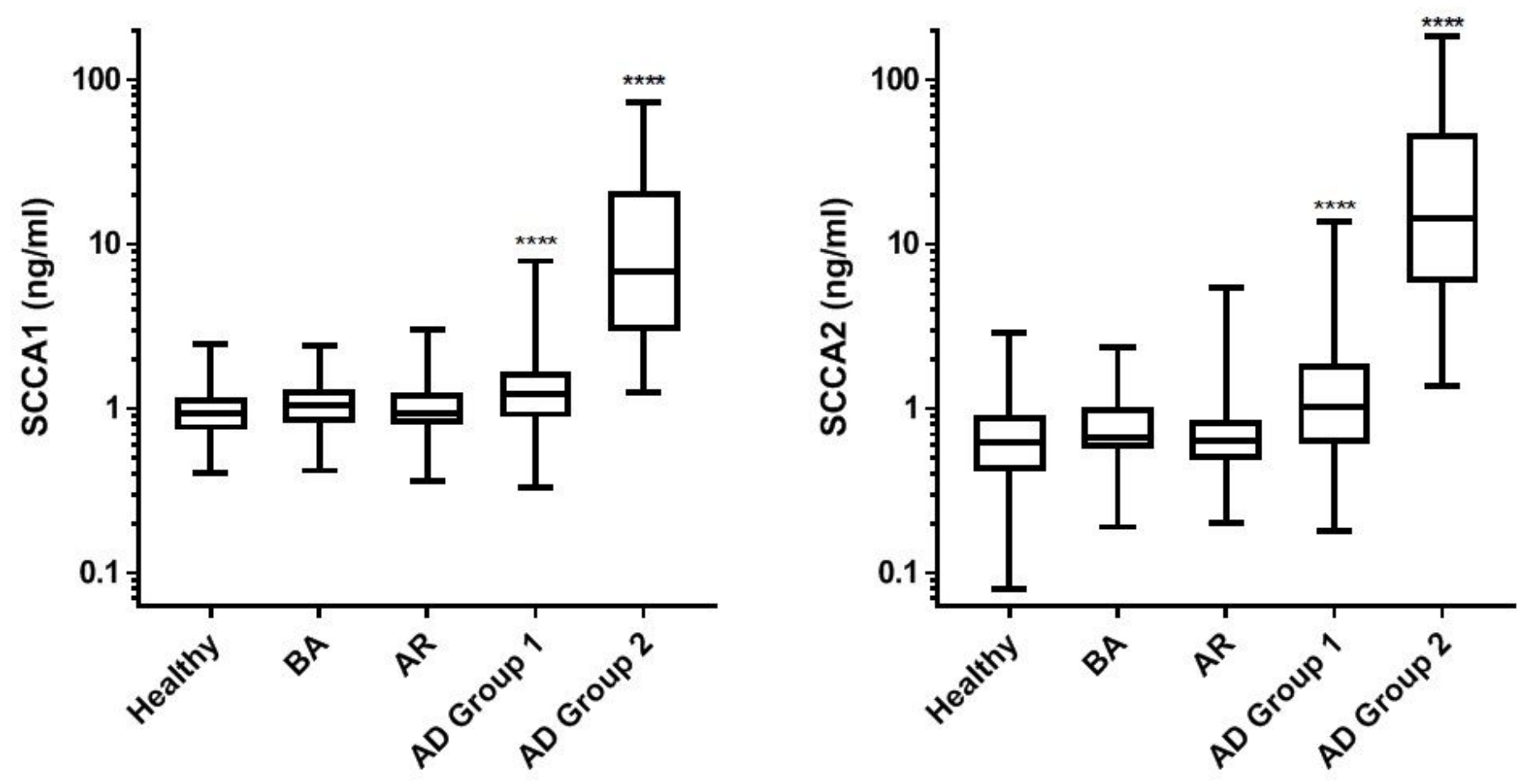

Figure 2

Baseline serum levels of SCCA1 (Fig. 1A) and SCCA2 (Fig. 1B) in the study participants. The geometric mean serum levels of SCCA 1 and SCCA2 differed among the 5 participant groups $(p<0.0001$; analysis of variance). 

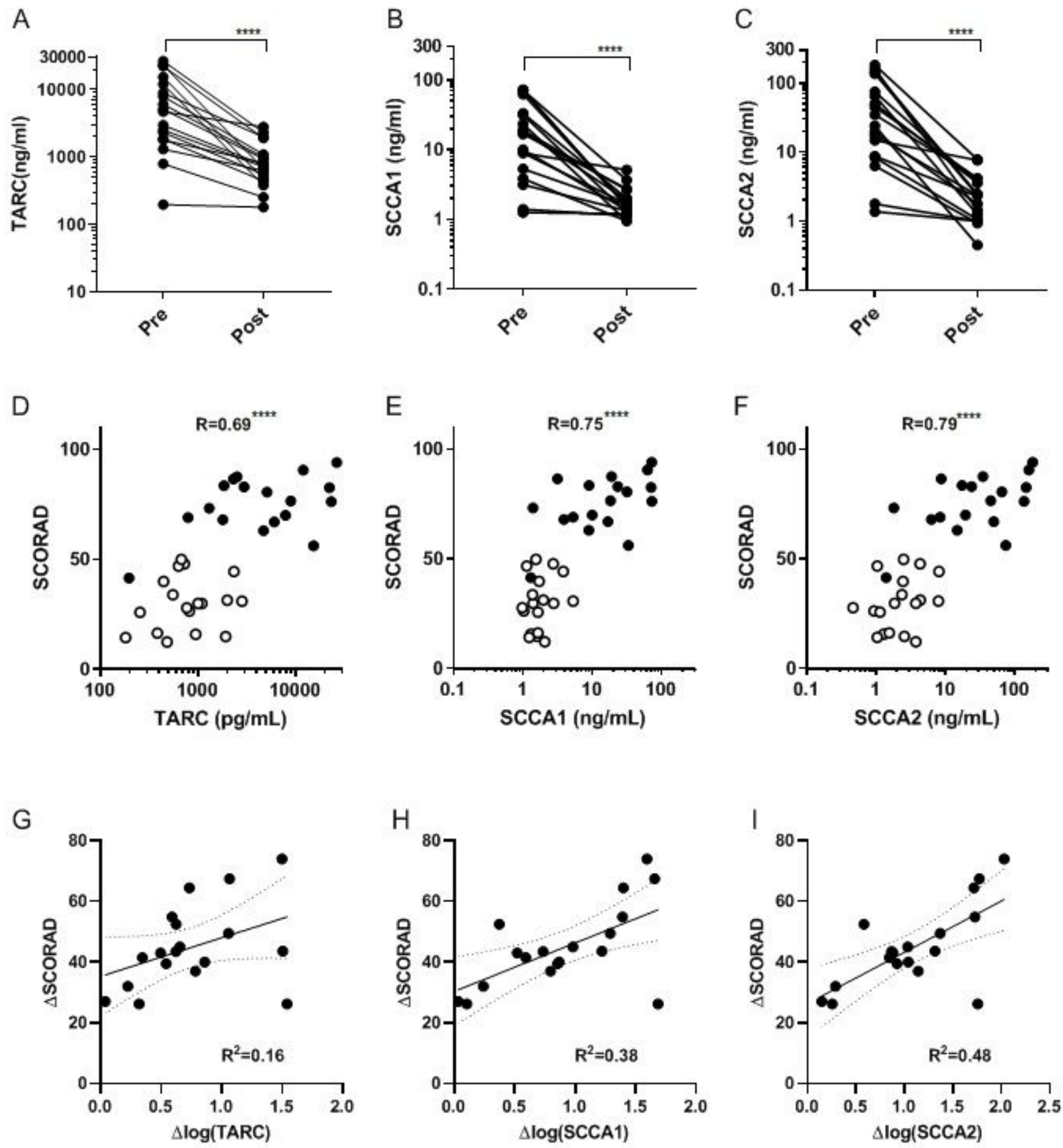

Figure 3

Serum levels of TARC, SCCA1 and SCCA2 before and after treatment of severe AD patients Changes in the serum levels of TARC (A), SCCA1 (B) and SCCA2 (C) between the beginning and end of hospitalization. ${ }^{\star} * \star \mathrm{P}<0.0001$ Wilcoxon matched-pairs signed rank test. Relationships between the decrease in the severity scoring of atopic dermatitis (SCORAD) index and the decreases in serum levels of TARC (D), SCCA1 (E) and SCCA2 (F) during hospitalization. Closed and open circles indicate the values at the beginning and end of hospitalization, respectively. ${ }^{* *} \mathrm{P}<0.0001$ Spearman's correlation test. The $X-$ 
axes show the decrease in the SCORAD index, while the Y-axes show the decrease in the logarithmically transformed serum levels of TARC $(\mathrm{G}), \operatorname{SCCA} 1(\mathrm{H})$ and SCCA2 (I), respectively.

\section{Supplementary Files}

This is a list of supplementary files associated with this preprint. Click to download.

- SupplementaryTablesAACIfinal.docx 